\title{
Controlling formation of metal ion adducts and enhancing sensitivity in Liquid Chromatography Mass Spectrometry
}

\author{
Padma Marwah \\ Center for Coastal Studies, Texas A\&M University, Corpus Christi, TX 78412 \\ Current Address: 10F Gounlloy, Nuvem, South Goa-403713, India \\ Ashok K. Marwah* \\ 10F Gounlloy, Nuvem, South Goa-403713, India \\ Paul V. Zimba \\ Center for Coastal Studies, Texas A\&M University, Corpus Christi, TX 78412 \\ *Corresponding author. E-mail: akmarwah@gmail.com
}

\begin{abstract}
Formation of metal ion adducts in mass spectrometry, particularly in electrospray ionization liquid chromatography mass spectrometry (ESI-LC-MS), is a nightmare scenario for an analyst dealing with quantitative analysis. We have studied in detail the metal adduct formation and concluded that the use of fluorinated alkanoic acids along with formic acid and volatile ammonium salts was extremely useful in suppressing metal adduct formation in positive ion mode of ESI-LC-MS. The extremely high electronegativity of fluorine atom and unique electrostatic nature of $\mathrm{C}-\mathrm{F}$ bond coupled with stereo-electronic interactions with neighboring bonds or lone pairs enables the polyfluorinated alkanoic acids in trapping highly electropositive ions $\left(\mathrm{Na}^{+}, \mathrm{K}^{+}\right)$thereby letting proton do its job efficiently. Addition of formic acid, trifluoroacetic acid, heptafluorobutyric acid and ammonium acetate was found to be extremely effective in controlling metal ion adducts and producing $[\mathrm{M}+\mathrm{H}]^{+}$ ions almost exclusively resulting in significant increase in the sensitivity. This technique has been successfully used in our laboratory for the estimation of targeted and nontargeted analysis of pesticides, marine toxins, drugs and pharmaceuticals etc. in various matrices including environmental waters using liquid chromatography-time of flight mass spectrometer operated in all ion acquisition mode and triple quadruples (QQQ) in multiple reaction monitoring (MRM) mode.
\end{abstract}

Keywords: Ammonium acetate; Electrospray ionization (ESI), Forensic sciences. Formic acid; Heptafluorobutyric acid (HFBA); Liquid chromatography-Mass spectrometry (LCMS); Metal ion adducts, Sensitivity, TOF

\section{Article Info}

https://doi.org/10.31018/

jans.vi.2277

Received: May 1, 2020

Revised: May 25, 2020

Accepted: May 29, 2020

\section{How to Cite}

Marwah, P. et al. (2020). Controlling formation of metal ion adducts and enhancing sensitivity in Liquid Chromatography Mass Spectrometry. Journal of Applied and Natural Science, 12(2): 180 - 192 https://doi.org/10.31018/ jans.vi. 2277

\section{INTRODUCTION}

Mass spectrometry is a highly accurate and sensitive technique to measure mass-to-charge $(\mathrm{m} / \mathrm{z})$ ratios of analytes and their fragments (Siuzdak, 2003; Thompson, 2018; Vijlder et al., 2018). Soft ionization techniques such as electrospray ionization produce charged species by adduct formation $\left([\mathrm{M} \pm n \mathrm{H}]^{\mathrm{n}}\right.$ where $\left.\mathrm{n} \geq 1\right)$, the most common adduct in positive ion mode being proton giving rise to even electron species $\left([M+n H]^{n+}\right.$ where $\left.n \geq 1\right)$. (Holcapek and Byrdwell, 2017) However, several other adduct ions such as $[\mathrm{M}+\mathrm{Na}]^{+},[\mathrm{M}+\mathrm{K}]^{+}$, or $\left[\mathrm{M}+\mathrm{NH}_{4}\right]^{+}$or their dimers etc. are also often observed in mass spectra. Sodium and potassium originate from the biological matrix, from the glass containers used or from the glass components of some mass spectrometers, whereas ammonium ions chiefly result from the addition of ammonium acetate or ammonium formate to the mobile phase (s). The sodium adduct, $[\mathrm{M}+\mathrm{Na}]^{+}$, is the most commonly seen alkali metal adduct which can be attributed to the ubiquitous presence of sodium. Although the exact mechanism involved in adduct formation of alkali metals is not clearly understood, hydroxyl, carboxyl, carbonyl, ether and ester groups are believed to be responsible for binding the alkali metal ions (Kruve et al., 2013; Kruve and Kaupmees, 2017).

The formation of adduct ions other than that of protons has its own advantages and disadvantages (Lambert, 2004; Vogesser and Seger, 2010). In a qualitative assessment, especially those dealing with analysis of unknown compounds, presence of more than one adduct ion provides a much needed extra proof for the molecular weight of the unknown compound in question, and is sometimes achieved by addition of 
micro molar quantities of semi volatile sodium salts such as sodium acetate to the mobile phase. Occasionally sodium adduct formation has been used to reduce insource fragmentation of labile compounds (Mortier et al., 2005; Yamin et al,. 2019). Electrospray ionization (ESI), in positive ion mode, the most commonly used manifestation of MS/LC-MS, has been plagued by the tendency of various analytes, particularly oxygen rich compounds, to form metal adducts, often undesirable. This metal adduct formation process is seldom reproducible and metal adducts in general and sodium adducts in particular are poor substrates for multiple reaction monitoring (MRM) extensively used in quantitative analysis (forensic, environmental, pharmaceutical sciences etc.), hence not recommendable for the quantification of organic compounds. Difficult to fragment metal adducts fail to provide good fragments in reasonable abundances thus making it hard to identify and quantify known compounds. Exclusive formation of metal adducts compounds the problems rendering structure elucidation of the unknown compounds rather difficult. This formation of unwanted metal adducts causes a loss of sensitivity as well as accuracy and precision in the quantitation of analyte(s). Post column addition of formic acid has been recommended to control the formation of unwarranted adducts (Dowling, 2017).

However, quantitative analytical studies become more complex when multiple adducts are present (cf. forensic studies). Alkali metal adduct formation often adds to the complexity and uncertainties of quantitative LC-MS, since metal adduct formation process is seldom reproducible at a given concentration of analytes and ratio of abundances of proton adducts and alkali metal adducts are rarely reproducible at different concentration levels used for plotting of calibration curves for quantitation. Mobile phase preparation and composition strongly influence chromatographic separation and adduct formation in electrospray ionization MS. Even slight change in mobile phase composition may affect the separation of complex mixtures as well as the extent of adduct formations. The formation of $[\mathrm{M}+\mathrm{Na}]^{+}$ions has been found to vary by up to a factor of four, depending on the mobile phase composition (Leitner et al., 2007). Presence of multiple adducts often leads to calibration curves which are either non-linear and/or difficult to reproduce. Metal adducts, in general, and sodium adducts, in particular, are also poorly fragmented, and therefore are not good substrates for multiple reaction monitoring (MRM) approaches and not recommended for mass based (MS/MS and/or pseudo MS/MS) methods used for the quantification of organic compounds using liquid chromatography-mass spectrometry. Sodium adduct formation efficiency of neutral compounds has been studied. Oxygen rich com- pounds were found to have higher efficiency of sodium adducts $[\mathrm{M}+\mathrm{Na}]^{+}$formation than nitrogen containing compounds because of the higher partial negative charge on oxygen atoms and competition from protonation in the case of nitrogen bases. Chelating abilities strongly increase $[\mathrm{M}+\mathrm{Na}]^{+}$ adduct formation efficiency. Quantitative and reproducible formation of $[\mathrm{M}+\mathrm{Na}]^{+}$adduct formation has been occasionally achieved by addition of micromolar quantities of sodium salts (Kruve et al., 2013; Kruve and Kaupmees, 2017) but the problems of having good qualifiers and loss in sensitivity remain.

The most common source of metal contamination is from water/solvent bottles and laboratory glassware. Biological samples often have a high endogenous concentration of various salts while other salts may be added during sample preparation. Clinical patient samples, forensic analysis samples, such as urine, plasma and other biological tissues, vary widely in salt concentrations and the variability of metal adduct ion formation from one sample to another has often been observed leading to non-linear behavior of the compounds and/ or to inaccurate quantitative results. Rarely, alkali metal adducts result in higher sensitivity compared to protonation (or deprotonation) and occasionally have been used for quantitative analysis (Marwah et al., 2001), but the inability of metal adducts in general and sodium adducts in particular to undergo collision induced dissociation makes it difficult to assign qualifiers to the molecule being quantified leading to a lack of specificity and selectivity. Scientific ethics and regulatory agencies require that one or more qualifiers be assigned to the compound being investigated unless precluded by the demanding chemistry of the analyte in question. Lithium adducts, $[\mathrm{M}+\mathrm{Li}]^{+}$, obtained by addition of lithium acetate to the mobile phase are better substrates for collision induced fragmentation (Hua et.al,. 2014), but presence of lithium isotopes ( ${ }^{6} \mathrm{Li} 7.6 \%,{ }^{7} \mathrm{Li} 92.4 \%$ ) causes some loss in sensitivity $(\sim 8 \%)$ as well as introduces its own complications when working with accurate mass instruments (TOF, QTOF etc.).

To overcome the metal adducts and linearity problems, several methods have been published that were not very effective in preventing adduct formation. These methods involve use of formic or acetic acid in combination with their volatile salts (viz. ammonium formate or ammonium acetate). Use of ammonium formate or ammonium acetate in mobile phase can make the adduct formation reproducible between samples. However, there still remains a significant degree of adduct formation with loss of sensitivity (Erngren et al., 2019, Schug and McNair, 2002) Addition of ascorbic acid, to the mobile phase has been recommended for controlling adduct formation (Becker, 2011) but ascorbic acid being a strong antioxi- 
dants can chemically interfere with analytes. We undertook a detailed study of metal adduct formation using various additives such as formic, acetic and fluorinated alkanoic acids, and their volatile ammonium salts and were eventually able to suppress the undesired adduct formation in ESI -LS-MS to a great extent.

\section{MATERIALS AND METHODS}

A representative group of about ten organic compounds having abundant formation of sodium ion adducts was selected from a pool of about fifty organic compounds consisting of pesticides, pharmaceuticals and personal day care products. Extremely polar and highly water soluble herbicides such as glyphosate, aminomethylphosphonic acid (AMPA) and a complex marine toxin (PaceficCiguatoxin-1, molecular weight 1100.576) were also selected for this study. The compounds having abundant formation of sodium adducts under regular conditions of LC-MS were: carbofuran, carisoprodol, dimethoate, malathion, metazachlor, metosulam, metoxuran, pyraclostrobin, strophanthidin, glyphosate, AMPA, and ciguatoxin-1 (Pacific). A reference standard solution $(500 \mathrm{pg} /$ $\mathrm{mL}$ ) was prepared and stored in freezer at $-20^{\circ} \mathrm{C}$. Ammonium formate, ammonium acetate, ammonium trifluoroacetate, acetic acid, formic acid, trifluoroacetic acid, heptafluorobutyric acid, nonafluorovaleric acid, chlorodifluoroacetic acid, pentafluoropropionic acid, methanol, ethanol, isopropanol and acetonitrile were all HPLC grade or better (LC-MS grade).and were obtained from Sigma-Aldrich, USA. Ultra-pure water (18.2 M $\mathrm{M}$ $\mathrm{cm})$ filtered through $0.2 \mu$ filter was used throughout the study.

Instrumentation: High performance liquid chromatography-time-of-flight-mass spectrometer (HPLC-MS-TOF, Model 6230) and triple quadruple (6420) system manufactured by Agilent Technologies Inc. Palo Alto, CA, USA, were used for this study. The 1290 series HPLC comprised of a Binary pump with an online degasser, a heated column compartment, an auto sampler with thermostat. MS-TOF system was equipped with Agilent jet-stream (AJS) dual ESI detector. Data were acquired and processed using Mass Hunter software (version B.07.00). Various operating parameters of HPLC and TOF-MS were thoroughly studied and optimized for the analysis of various compounds under investigation, and are specifically discussed below.

Analytical conditions:

HPLC: Chromatography was performed on a Poroshell-120 EC C-18 column $(2.1 \times 150 \mathrm{~mm}, 2.7$ $\mu \mathrm{M}, 120 \AA$, Agilent Technologies Inc. Palo Alto, CA, USA) protected by an Agilent EC $2.7 \mu \mathrm{m}$ C18 guard column, $(3 \times 5 \mathrm{~mm})$ at a flow rate of $0.5 \mathrm{ml} /$ min and a column temperature of $50^{\circ} \mathrm{C}$. The injected sample volume was $4 \mu \mathrm{L}(2000 \mathrm{pg}$ on col- umn). A mobile phase of water-methanol or wateracetonitrile was used with a gradient elution (5$95 \%$ organic, v/v) in a 10 min run time. Replacing methanol with acetonitrile and vice versa produced similar results though more formation of sodium adduct was observed when methanol was used. Various combinations of additives (ammonium formate, ammonium acetate, ammonium trifluoroacetate, trifluoroacetic acid, acetic acid, formic acid, petafluoropropionic acid, heptafluorobutyric acid etc.) as disclosed in various experiments below were added to mobile phase(s) and/or solution of analyte(s) to control the formation of metal adducts. Analytes were dissolved in initial composition of mobile phase or in $20 \%$ methanol.

MS-TOF: The dual electrospray (dual ESI-positive mode) parameters for AJS were: drying gas $\left(\mathrm{N}_{2}\right) 8$ $\mathrm{L} / \mathrm{min}$, gas temperature $325^{\circ} \mathrm{C}$, nebulizer $35 \mathrm{psi}$, sheath gas temperature $350^{\circ} \mathrm{C}$, sheath gas flow $11 \mathrm{~L} / \mathrm{min}$, Vcap 2500-3500 V, nozzle voltage 500$1000 \mathrm{~V}$, fragmentor $150 \mathrm{~V}-250 \mathrm{~V}$. Analysis was carried out in positive lon mode. Data points collection was 6 spectra/min (2170 transients/ spectrum). Dual ESI with its reference nebulizer provided continuous flow of reference ions $(\mathrm{m} / \mathrm{z}$ 121.0508 and 922.0098) during the entire run time. MS-TOF was tuned (mass range 100-3200 at $2 \mathrm{GHz}$ mode) weekly and calibrated (mass range $100-1700$ at $2 \mathrm{GHz}$ mode) every day before analysis. For reproducibility and consistency, ESI spray chamber was cleaned with isopropanolwater $(1: 1, v / v)$ every day before use. Data files were analyzed against commercially available database of the compounds being studied. Compounds were identified on the basis of accurate mass measurement ( $<5 \mathrm{ppm})$, matching retention times, isotopic patterns and fragmentation patterns.

\section{RESULTS AND DISCUSSION}

It has been observed that dissolution from glassware can introduce micromolar quantities of silicates within a few hours, thereby releasing trace amounts of sodium ions into the water. The extent of dissolution has been found to be dependent, among others, on contact time, salt content and was greatly influenced by the $\mathrm{pH}$ of the solution, higher the $\mathrm{pH}$ faster and higher the contamination (Bohrer et al., 2008). It is a common knowledge that glass bottles containing sodium hydroxide develop corroded surfaces because of high rate of dissolution of glass at extremely high $\mathrm{pH}$ (14.0). We agree with the authors that "pure" water in glass vessel does not exist, but is rather an extremely dilute aqueous solution of glass's components. (Bester-Rogac, 2014; Zhang et al., 1999). It has been a common practice in our lab to add acid (formic or acetic) first into the solvent bottle followed by addition of water so as to keep $\mathrm{pH}$ low, thereby partially controlling the dissolution of 
glass in water since the solubility of sodium silicate is highly dependent on $\mathrm{pH}$. By adding acid first we have been able to partially but neither efficiently nor reproducibly control the formation of sodium adducts.

A group of about fifty organic compounds (Table 1 to 4) including polar to non-polar, non-volatiles to semi volatiles, good to poor ionizers were studied by LC-MS-ESI for metal adduct formation using conventional LC-MS mobile phases comprising of water/methanol/acetonitrile containing conventional quantities of formic acid, or acetic acid, with or without ammonium acetate or ammonium formate. A representative group of about ten compounds (carbofuran, carisoprodol, dimethoate, malathion, metazachlor, metosulam, metoxuran, pyraclostrobin and strophanthidin), which were observed to consistently form appreciable amounts of metal adducts and were selected for further detailed studies, turned out to be an eye opener from organic chemistry point of view. This group consisted of three aromatic nitrogen heterocycles, (metosulam, metazachlor and pyraclostrobin) known for bad peak shapes, a benzofuran derivatives (carbofuran) which is a poor substrate for LC -MS, strophanthidine, an oxygen rich steroidal cardenolide prone to sodium adduct formation, an aliphatic skeletal muscle relaxant (carisoprodol) an aliphatic diamide is a rather poor substrate for ESI; phospho-pesticides viz. malathion (boiling point $156{ }^{\circ} \mathrm{C}$ ), dimethoate (boiling point $117^{\circ} \mathrm{C}$ ), both being challenging candidates for extraction from matrix, liquid chromatography and ESI-MS by virtue of being semi volatile. Also studied were glyphosate, a widely used water soluble, amphoteric, highly polar broad spectrum herbicide and its main metabolite aminomethylphosphonic acid (AMPA) a highly polar, amphoteric, difficult to retain on column compound (Jaikwang, 2020). The vary fact that we were able to grately suppress and control formation of metal ion adducts in such a hetrogenous group of compounds scattered all over the domain of organic chemistry itself speaks of the robustness, efficiency usefulness of the technique developed by us as discussed subsequently.

The extent of formation of sodium adduct was found to be inconsistent and did not follow any set pattern or norm under conventional techniques of mass spectrometry using volatile solvents (chiefly methanol and acetonitrile) and volatile organic acids (acetic and formic acids) and volatile buffers/ mobile phase additives (ammonium acetate and ammonium formate). This behavior of erratic formation of sodium adducts is often observed in mass spectrometric studies and is a major source of error often leading to unacceptable values of standard deviations (poor reproducibility), accuracy and precision during quantitative estimation of organic compounds and nonlinear behavior (Lambert, 2004).

Table 1 shows the formation of sodium and potassium adducts using conventional LCMS mobile phases. Use of acetic acid or formic acid as mobile phase additive resulted into formation of appreciable amounts of sodium and potassium adducts and sometimes the sodium adduct was found to be the base peak (carbofuran and metazachlor), and occasionally sodium adduct was the only major ion ((strophanthidin, $100 \%[\mathrm{M}+\mathrm{Na}]^{+}$not even trace of $\left.[\mathrm{M}+\mathrm{H}]^{+}\right)$in the mass spectrum). Use of methanol, a protic solvent, resulted into higher formation of sodium adducts than acetonitrile, which probably can be ascribed to the better solvation of ions in aqueous methanolic (protic) medium. Addition of ammonium acetate or formate reduced the adduct formation to some extent, but could not eliminate it. However addition of ammo-

Table 1. Formation of Metal adducts $\left([\mathrm{M}+\mathrm{Na}]^{+}+[\mathrm{M}+\mathrm{K}]^{+}\right)$in ESI-LC-MS using various combinations of formic and acetic acids and ammonium formate, ammonium acetate and ammonium trifluoroacetate.

\begin{tabular}{lcccccc}
\hline & \multicolumn{5}{c}{ Metal adducts $([\mathbf{M + N a}+\mathbf{+}$ and $[\mathbf{M + K}+\mathbf{+})$, Relative Peak abundances } \\
\cline { 2 - 7 } Compound & $\mathbf{I}$ & $\mathbf{I I}$ & III & IV & V & VI \\
\hline Carbofuran & 16.9 & 9.0 & 3.7 & 0.4 & 0.1 & 0.0 \\
Carisoprodol & 110.3 & 281.1 & 159.6 & 28.0 & 10.7 & 5.8 \\
Dimethoate & 40.2 & 32.4 & 19.9 & 1.1 & 0.2 & 0.0 \\
Malathion\# & 48.7 & 24.7 & 7.8 & 5.2 & 0.4 & 0.0 \\
Metazachlore & 158.5 & 100.9 & 48.9 & 3.6 & 0.5 & 0.2 \\
Metosulam & 4.2 & 2.7 & 2.4 & 3.8 & 1.7 & 0.1 \\
Metoxuron & 2.4 & 1.5 & 0.9 & 0.4 & 0.1 & 0.1 \\
Pyraclostrobin & 10.1 & 4.9 & 2.2 & 3.6 & 0.0 & 0.0 \\
Strophanthidin & 21.6 & $1000^{*}$ & 29.5 & 17.5 & 8.1 & 4.0 \\
\hline
\end{tabular}

Mobile phase additives. I, $0.1 \%$ formic acid (v/v); II $-0.1 \%$ acetic acid; III $-0.1 \%$ acetic acid with $2 \mathrm{mM}$ ammonium acetate; IV - $0.1 \%$ formic acid with $2 \mathrm{mM}$ ammonium acetate; $\mathbf{V}-0.02 \%$ Formic acid with $4 \mathrm{mM}$ ammonium trifluoroacetate; $\mathbf{V I}-0.02 \%$ Formic acid with $4 \mathrm{mM}$ ammonium trifluoroacetate and $2 \mathrm{mM}$ ammonium acetate. ${ }^{\#}$ Formation of ammonium adduct was observed; *Exclusive formation of $[\mathrm{M}+\mathrm{Na}]^{+}$. $[\mathrm{M}+\mathrm{H}]^{+}$was assigned $100 \%$ abundances. 
nium trifluoroacetate to the mobile phase drastically reduced the formation of sodium and potassium adducts as it introduced a trifluoromethyl compound in the mobile phase (discussed subsequently), and further improvement was observed when both ammonium trifluoroacetate and ammonium acetate/formate along with formic acid were added to the mobile phase (Table 1).

Ammonium acetate and ammonium formate are commonly used mobile phase additives in LC-MS (Konermann, 2017). They help in ionization and depending upon the $\mathrm{pH}$ value, they act as buffers as well. They also have the capacity to mask reversed phase residual silanol groups thus improving chromatography and peak shape. (Escott and Chandle, 1989). Inclusion of ammonium acetate along with formic acid increases the efficiency of ionization and gives satisfactory sensitivity sometimes. It is well documented that the use of ammonium acetate not only suppresses the metal ion adduct formation but also prevents the adduct formation involving the anion of strong acids (e.g., phosphate, trifluoroacetate anions, etc.) and ionized basic residues (Banerjee and Mazumdar, 2012). It has been reported that the presence of formic acid in the mobile phase improved peak shapes and reduced matrix effects without significantly decreasing response (Gao et al,. 2010).

Fluorine by virtue of being most electronegative element (4.0 for fluorine vs. 2.5 for carbon) introduces ionic character to the carbon-fluorine bond $\left(\mathrm{C}^{\delta^{-}}-\mathrm{F}^{\delta^{-}}\right)$The electron density is concentrated around the fluorine, leaving the carbon relatively electron deficient. The partial negative charge on the fluorine and partial positive charge on carbon produces strong electrostatic force of attraction between them resulting in unusual bond strength of a highly polarized $\mathrm{C}^{\delta^{+}-} \mathrm{F}^{\delta-}$ bond. This polarity does not permit lone pair donation from fluorine making it a poor coordinator. However, the $\mathrm{C}-\mathrm{F}$ bond has interesting properties which can be understood either in terms of electrostatic/dipole interactions or by considering stereoelectronic interactions (hyperconjugation) with neighboring bonds or lone pairs (O'Hagen, 2008; Lemal, 2004). The $\mathrm{C}^{\delta+}-\mathrm{F}^{\delta-}$ dipole interacts with other approaching dipoles or charges (e.g. $\mathrm{N}+, \mathrm{O}+, \mathrm{M}+$ ) via electrostatic interactions. As mentioned above, the fluorine lone pairs are held by the nucleus (electronegativity) and the adjacent partially charged $\left(\mathrm{C}^{\delta^{+}}\right)$carbon, so they are hardly polarized and are poor substrates. No wonder, fluorine hardly ever acts as a $\mathrm{H}$-bond acceptor (Dunitz and Taylor, 2006). Based on the above discussion, it is reasonable to conclude that $\mathrm{C}-\mathrm{F}$ dipole can interact electrostatically with metal ions $\left(\mathrm{Na}^{+}, \mathrm{K}^{+}\right.$etc. present in the vicinity), thereby preventing them from forming metal ion adducts $\left([\mathrm{M}+\mathrm{Na}]^{+},[\mathrm{M}+\mathrm{K}]^{+}\right.$ etc.) in mass spectrometric analysis. Therefore, we decided to study the role of trifluoro acetic acid and its higher analogues such as pentafluoropropanoic acid (PFPA), heptafluorobutyric acid (HFBA) and nonafluorovaleric acid (NFVA) on the formation of metal ion adducts in LC-MS. Perfluorinatedalkanoic acids, particularly heptafluorobutyric acid (HFBA) have been extensively used in GCMS as derivatizing agent (Turkmen et al., 2019) and in LC-MS as ion pair reagents as well as additive in mobile phase (Murtada et al,. 2019; Jaikwang et al., 2020; Dowling, 2017).

Trifluoro acetic acid (TFA, 0.01\%, $100 \mathrm{ppm}$ v/v) as additive was found to be insufficient for good chromatography as well as suppression of metal adduct formation (Table 2), but increasing its concentration, as is well known, resulted in too much back ground noise and signal suppression (Marwah et al., 2002), and the use of ammonium acetate helps in preventing that sensitivity loss (Shou and Naidong, 2005) to some extent. Based on our earlier discussion about the electrostatic

Table 2. Formation of Metal adducts $\left([\mathrm{M}+\mathrm{Na}]^{+}+[\mathrm{M}+\mathrm{K}]^{+}\right)$in ESI-LC-MS using various combinations of fluorinated acetic acids with or without ammonium salts.

\begin{tabular}{cccccc}
\hline \multirow{2}{*}{ compound } & \multicolumn{4}{c}{ Metal adducts $([\mathbf{M + N a}]+$ and $[\mathbf{M + K}]+)$, Relative Peak abundances } \\
\cline { 2 - 5 } & VII & VIII & $\mathbf{I X}$ & $\mathbf{X}$ & $\mathbf{X I}$ \\
\hline Carbofuran & 9.1 & 0.0 & 0.0 & 0.0 & 0.0 \\
Carisoprodol & - & 2.0 & 2.7 & 4.6 & 4.3 \\
Dimethoate & 13.3 & 0.3 & 0.0 & 0.0 & 0.1 \\
Malathion\# & 54.4 & 0.8 & 0.1 & 0.2 & 0.4 \\
Metazachlor & 134.7 & 0.6 & 0.2 & 0.2 & 0.3 \\
Metosulam & 38.2 & 3.0 & 0.7 & 0.6 & 1.1 \\
metoxuron & 9.4 & 0.0 & 0.0 & 0.0 & 0.1 \\
Pyraclostrobin & & 0.4 & 0.1 & 0.2 & 0.2 \\
Strophanthidin & 100.0 & 6.8 & 4.3 & 3.5 & 5.7 \\
\hline
\end{tabular}

Mobile phase additives. VII, 0.01\% TFA (100 ppm, v/v); VIII - 0.1\% Formic acid, 10 ppm TFA and 2mM ammonium formate.; IX - 0.03\% Formic acid, 10 ppm TFA and 2mM ammonium acetate; $\mathbf{X}-0.1 \%$ formic acid , 10 ppm Difluoroacetic acid, $2 \mathrm{mM}$ ammonium acetate; $\mathbf{X I}-0.1 \%$ formic acid , 10 ppm Chlorodifluoroacetic acid, $2 \mathrm{mM}$ ammonium acetate ${ }^{\#}$ Formation of ammonium adduct was observed. $[\mathrm{M}+\mathrm{H}]^{+}$was assigned $100 \%$ abundances. 
behavior of $\mathrm{C}-\mathrm{F}$ bond and observation that ammonium salts of formic and acetic acid help in curtailing sodium adduct formation, we tried various combination of TFA, formic acid, ammonium trifluoroacetate and ammonium acetate and formate, and a cocktail of TFA (10 ppm), ammonium acetate $(2 \mathrm{mM})$ and formic acid was found to give very good results (Table 2). Formation of metal adducts was reduced to single digit; a few compounds (carbofuran and metoxuron) did not show any formation of sodium and potassium adducts. Difluoroacetic (DFA) acid and chlorodifluroacetic acids (CIDFA) also yielded very good results. Substantial reduction in adduct $[\mathrm{M}+\mathrm{Na}]^{+}$formation was observed (Table 2) for all compounds with near exclusive formation of $[\mathrm{M}+\mathrm{H}]^{+}$ions for several compounds resulting in a substantial gain in sensitivity. Achieving excellent results with such a complex array of compounds is an ode to rapid advancement in LC-MS and the wonderful capabilities of fluorinated alkanoic acids in presence of ammonium salts, in suppressing formation of metal ion adducts.

It has been reported that the $\mathrm{C}-\mathrm{F}$ bond also strengthens and shortens as more fluorine atoms are added to the same carbon atom. (O'Hagen, 2008). Therefore we expected that the strengthening of $\mathrm{C}-\mathrm{F}$ bond will result in stronger electrostatic forces in case of aliphatic organic acids substituted with many fluorine atoms, which should be able to trap the alkali metal ions much more efficiently. Of the various acids (pentafluoropropanoic acid (PFPA), heptafluorobutyric acid (HFBA) and nonafluorovaleric acid (NFVA) used, we found that HFBA at an unusually low concentration of 0.1 to $1 \mathrm{ppm}$ gave excellent results (Table 3 ) in presence of formic acid $(0.1 \%, 1000 \mathrm{ppm})$, TFA
(10 ppm) and ammonium acetate $(2 \mathrm{mM})$, henceforth referred to as preferred cocktail number one. Figures 1 to 8 illustrate the mass spectra of the representative organic compounds obtained using conventional mobile phases as well as using a preferred cocktail number one. Near total absence of metal (sodium and potassium) adducts is clearly visible most of the time.

We then analyzed about fifty compounds of varying chemistries (pesticides, analgesics, drugs and pharmaceuticals, herbicides, alicyclic compounds etc.) using this preferred cocktail number one consisting of TFA, HFBA, formic acid and ammonium acetate (Table 4 ). Most of the compounds ( $>88 \%$ ) yielded exclusive formation of $[\mathrm{M}+\mathrm{H}]^{+}$and did not show any formation of sodium or potassium adducts, four compounds ( $8 \%$ ) had less than $0.5 \%$ formation of $[\mathrm{M}+\mathrm{Na}]^{+}$. In this study carisoprodol and strophanthidin were found to exhibit a very stubborn behavior in always forming plenty of $[\mathrm{M}+\mathrm{Na}]^{+}$and $[\mathrm{M}+\mathrm{K}]^{+}$. However under the conditions of preferred cocktail number one, they produced insignificant amount of sodium adduct $(<2 \%)$. Occasional formation of ammonium adduct $\left[\mathrm{M}+\mathrm{NH}_{4}\right]^{+}$was observed for a few compounds such as malathion, and ciguatoxin, a marine algae (Yogi et al., 2011). Such exceptions need to be studied in detail individually. Nevertheless ammonium adducts were found to be good substrates for fragmentation reactions (collision induced dissociations) and produced good quality MS/MS spectra.

Therefore, it can be reasonably concluded that addition of volatile fluorinated organic acids to conventional mobile phases (methanol, acetonitrile, water, formic and acetic acids and their ammonium salts) used in LC-MS is a very useful technique for effectively creating good quality

Table 3: Formation of Metal adducts $\left([\mathrm{M}+\mathrm{Na}]^{+}+[\mathrm{M}+\mathrm{K}]^{+}\right)$in ESI-LC-MS using various combinations of formic, acetic acids and fluorinated alkanoic acids and ammonium formate, ammonium acetate and ammonium trifluoroacetate.

\begin{tabular}{cccccc}
\hline \multirow{2}{*}{ compound } & \multicolumn{5}{c}{ Metal adducts $([\mathbf{M + N a}]+$ and $[\mathbf{M + K}]+)$, Relative Peak abundances } \\
\cline { 2 - 6 } & XII & XIII & XIV & XV & XVI \\
\hline Carbofuran & 0.1 & 1.0 & 0.1 & 0.0 & 0.0 \\
Carisoprodol & 6.4 & 15.7 & 5.6 & 3.8 & 1.7 \\
Dimethoate & 0.1 & 0.4 & 0.1 & 0.1 & 0.0 \\
Malathion\# & 0.6 & 1.2 & 32.2 & 0.0 & 0.0 \\
Metazachlor & 0.5 & 0.6 & 0.4 & 0.3 & 0.1 \\
Metosulam & 2.2 & 3.1 & 1.3 & 1.0 & 0.4 \\
metoxuron & 0.1 & 0.3 & 0.1 & 0.1 & 0.0 \\
Pyraclostrobin & 0.2 & 0.4 & 0.2 & 0.1 & 0.1 \\
Strophanthidin & 1.8 & 7.0 & 9.1 & 4.2 & 1.6 \\
\hline
\end{tabular}

$[\mathrm{M}+\mathrm{H}]^{+}$was assigned $100 \%$ abundances. Mobile phase additives. XII, $0.1 \%$ Formic acid (100 ppm, v/v), pentafluoroproanoic acid (PFPA, 10 ppm) 2mM ammonium acetate; XIII - 0.05\% Formic acid, 10 ppm HFBA and $4 \mathrm{mM}$ ammonium formate; XIV - 10 ppm TFA, 0.1 ppm HFBA and $2 \mathrm{mM}$ ammonium acetate; XV - $0.1 \%$ formic acid, $0.1 \mathrm{ppm}$ HFBA, $2 \mathrm{mM}$ ammonium acetate and $0.1 \mathrm{mM}$ ammonium trifluoroacetate $\mathbf{X V I}-0.1 \%$ formic acid, 10 ppm TFA, 0.1 ppm HFBA, 2 mM ammonium acetate ${ }^{\#}$ Formation of ammonium adduct was observed. 
Marwah, P. et al. / J. Appl. \& Nat. Sci. 12(2): 180 - 192 (2020)

Table 4. Reduction in formation of metal ion adducts $\left([\mathrm{M}+\mathrm{Na}]^{+}+[\mathrm{M}+\mathrm{K}]^{+}\right)$in ESI-LC-MS using polyfluorinated alkanoic acids.

\begin{tabular}{|c|c|c|c|c|c|c|c|}
\hline \multirow{2}{*}{ Name } & \multirow{2}{*}{ Mass } & \multirow{2}{*}{ RT } & \multirow{2}{*}{$\begin{array}{c}\text { Diff } \\
(\mathrm{ppm})\end{array}$} & \multicolumn{3}{|c|}{ Percentage Relative Abundance } & \multirow{2}{*}[M+K]{+} \\
\hline & & & & {$[\mathrm{M}+\mathrm{H}]+$} & {$[\mathrm{M}+\mathrm{NH} 4]+$} & {$[\mathrm{M}+\mathrm{Na}]+$} & \\
\hline Acetylcodeine & 341.1629 & 3.94 & 0.7 & 100 & 0 & 0.0 & 0 \\
\hline Aminocarb & 208.1214 & 1.77 & 0.9 & 100 & 0 & 0.0 & 0 \\
\hline Atrazine & 215.0945 & 7.06 & 3.3 & 100 & 0 & 0.0 & 0 \\
\hline Atropine & 289.168 & 3.35 & 0.7 & 100 & 0 & 0.0 & 0 \\
\hline Benzoylecgonine & 289.1318 & 3.60 & 1.5 & 100 & 0 & 0.0 & 0 \\
\hline Buprenorphine & 467.3037 & 6.21 & 0.4 & 100 & 0 & 0.0 & 0 \\
\hline Caffeine & 194.0808 & 3.06 & 2.4 & 100 & 0 & 0.0 & 0 \\
\hline Carbofuran & 221.106 & 6.15 & 3.8 & 100 & 0 & 0.0 & 0 \\
\hline Carisoprodol & 260.1743 & 7.22 & 2.5 & 100 & 0 & 1.4 & 0.26 \\
\hline Clonidine & 229.0179 & 2.38 & 2.4 & 100 & 0 & 0.0 & 0 \\
\hline Cocaethylene & 317.1629 & 4.87 & 0.6 & 100 & 0 & 0.0 & 0 \\
\hline Cocaine & 303.1474 & 4.12 & 1.3 & 100 & 0 & 0.0 & 0 \\
\hline Cotinine & 176.0955 & 1.03 & 3.0 & 100 & 0 & 0.0 & 0 \\
\hline Dextroamphetamine & 135.1049 & 2.71 & 0.6 & 100 & 0 & 0.0 & 0 \\
\hline Dextromethorphan & 271.1941 & 5.85 & 1.7 & 100 & 0 & 0.0 & 0 \\
\hline Diazinon & 304.1015 & 9.35 & 1.5 & 100 & 0 & 0.0 & 0 \\
\hline Dihydrocodeine & 301.168 & 2.07 & 0.8 & 100 & 0 & 0.0 & 0 \\
\hline Dimethoate & 229.0002 & 4.06 & 2.6 & 100 & 0 & 0.0 & 0 \\
\hline EDDP & 277.1836 & 5.84 & 2.0 & 100 & 0 & 0.0 & 0 \\
\hline Hydrocodone & 299.1526 & 2.12 & 1.5 & 100 & 0 & 0.0 & 0 \\
\hline Imazalil & 296.0489 & 6.85 & 2.1 & 100 & 0 & 0.0 & 0 \\
\hline Imazapyr & 261.1118 & 3.85 & 1.6 & 100 & 0 & 0.0 & 0 \\
\hline Lidocaine & 234.1736 & 3.29 & 1.7 & 100 & 0 & 0.0 & 0 \\
\hline Malathion & 330.036 & 8.30 & -0.1 & 100 & 33.76 & 0.0 & 0 \\
\hline MDA & 179.0946 & 2.80 & 0.1 & 100 & 0 & 0.0 & 0 \\
\hline MDEA & 207.1265 & 3.23 & 2.6 & 100 & 0 & 0.0 & 0 \\
\hline MDMA & 193.111 & 2.90 & 3.6 & 100 & 0 & 0.0 & 0 \\
\hline Metazachlor & 277.0988 & 7.19 & 2.3 & 100 & 0 & 0.1 & 0 \\
\hline Methylphenidate & 233.1421 & 4.69 & 2.3 & 100 & 0 & 0.0 & 0 \\
\hline Metosulam & 417.0071 & 6.42 & 1.3 & 100 & 0 & 0.4 & 0 \\
\hline Metoxuron & 228.0672 & 5.26 & 2.7 & 100 & 0 & 0.0 & 0 \\
\hline Molinate & 187.1033 & 8.38 & 0.9 & 100 & 1.48 & 0.0 & 0 \\
\hline Morphine & 285.1369 & 1.45 & 1.3 & 100 & 0 & 0.1 & 0 \\
\hline Nicotine & 162.1162 & 0.87 & 3.0 & 100 & 0 & 0.0 & 0 \\
\hline Oxycodone & 315.1473 & 2.30 & 0.9 & 100 & 0 & 0.1 & 0 \\
\hline Phencyclidine & 243.1993 & 5.20 & 2.4 & 100 & 0 & 0.0 & 0 \\
\hline Phentermine & 149.121 & 2.82 & 3.7 & 100 & 0 & 0.0 & 0 \\
\hline Propafenone & 341.1995 & 6.98 & 1.3 & 100 & 0 & 0.0 & 0 \\
\hline Pyraclostrobin & 387.0965 & 9.50 & -5.3 & 100 & 0 & 0.1 & 0 \\
\hline Ritalinic acid & 219.1258 & 1.99 & -0.7 & 100 & 0 & 0.0 & 0 \\
\hline Strophanthidin & 404.2199 & 5.72 & 0.1 & 100 & 0 & 1.6 & 0 \\
\hline Thiabendazole & 201.0365 & 3.31 & 2.3 & 100 & 0 & 0.0 & 0 \\
\hline Verapamil & 454.2835 & 6.50 & 0.7 & 100 & 0 & 0.0 & 0 \\
\hline
\end{tabular}

Mobile phase: water-95\% methanol gradient ( 5 to $95 \%$ ) containing $0.1 \%$ formic acid , $10 \mathrm{ppm}$ TFA, $0.1 \mathrm{ppm}$ HFBA, 2 mM ammonium acetate. 
Marwah, P. et al. / J. Appl. \& Nat. Sci. 12(2): 180 - 192 (2020)
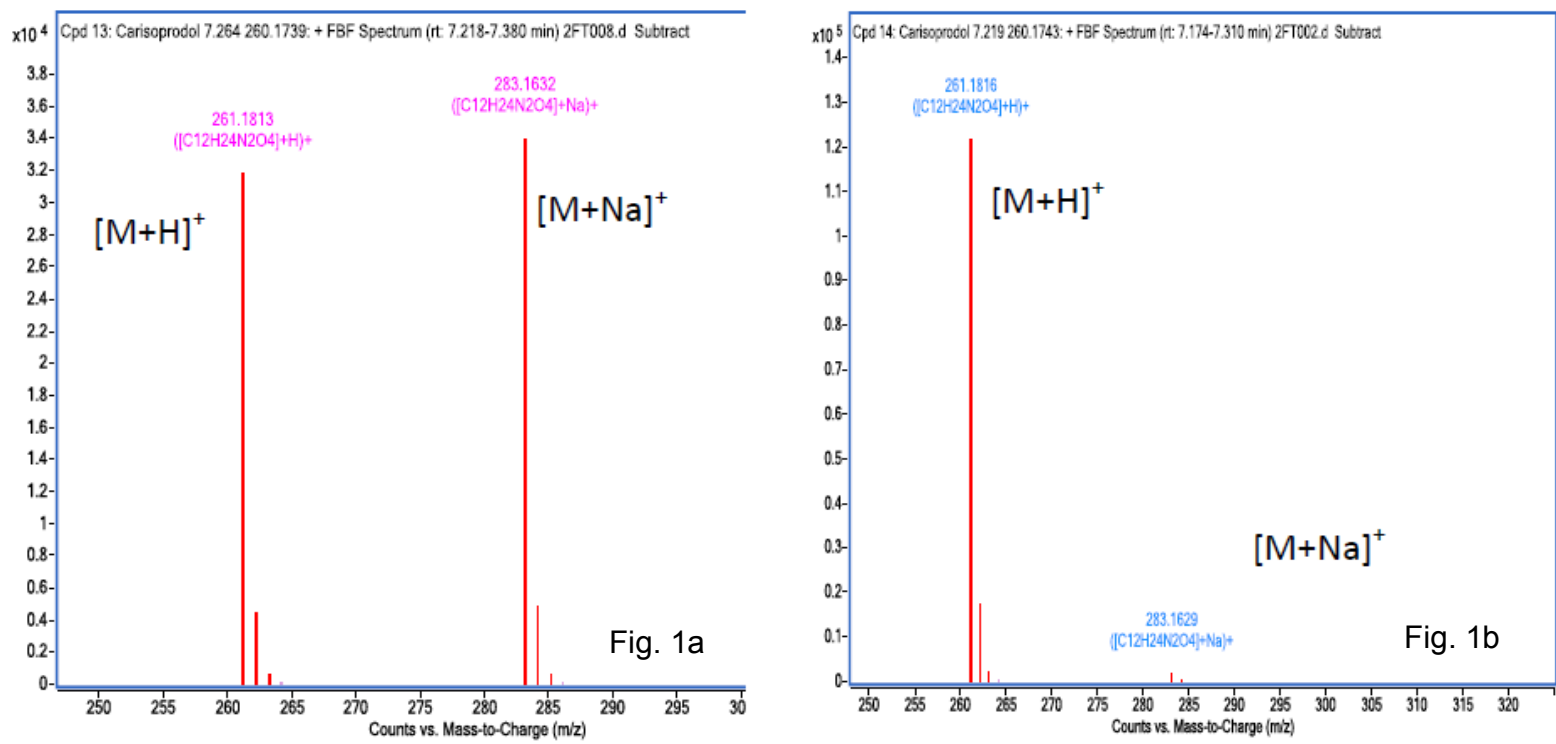

Fig. 1. Mass spectrum of carisoprodol obtained using water-95\% methanol with $0.1 \%$ acetic acid gradient (Fig 1a) and using a cocktail of formic acid, trifluoroacetic acid, heptafluorobutyric acid and ammoniumacetae in water-methanol gradient (Fig. 1b). Near absence of $[\mathrm{M}+\mathrm{Na}]^{+}$and total absence of $[\mathrm{M}+\mathrm{K}]^{+}$adducts was obseved. Complete LC-MS details under experimental section.
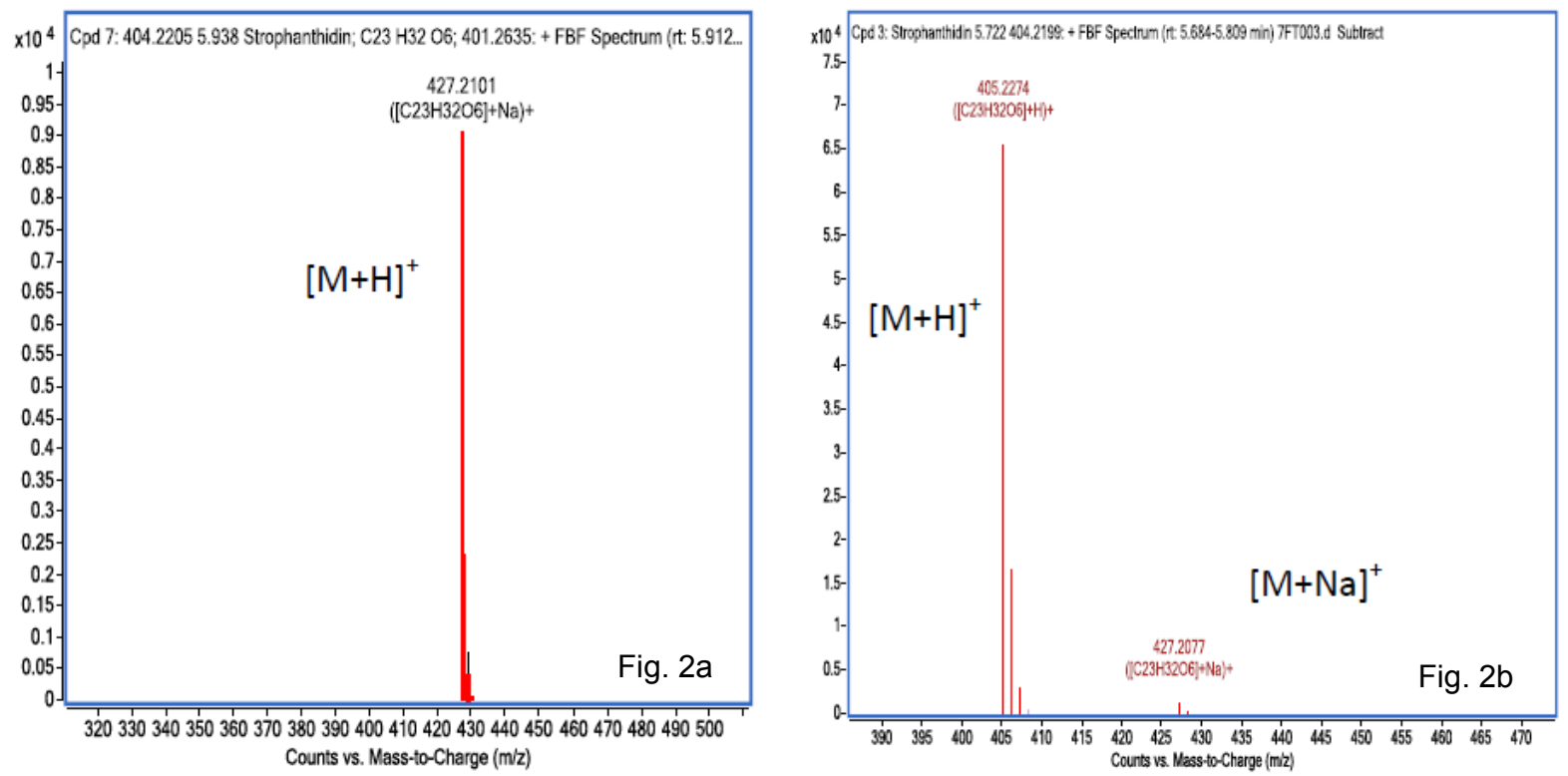

Fig. 2. Mass spectrum of strophanthidin obtained using water-95\% methanol with $0.1 \%$ acetic acid gradient (Fig 2a) and using a cocktail of formic acid, trifluoroacetic acid, heptafluorobutyric acid and ammoniumacetae in water-methanol gradient (Fig. 2b). Near absence of $[\mathrm{M}+\mathrm{Na}]^{+}$and total absence of $[\mathrm{M}+\mathrm{K}]^{+}$adducts was obseved. Complete LC-MS details under experimental section. Under conventional techniques $[\mathrm{M}+\mathrm{H}]^{+}$was either conspicuous by its absence or was formed in poor abundance.

peak chromatograms and purposefully controlling the formation of metal adducts in electrospray ionization in positive ion mode, thereby, facilitating formation of proton and occasionally ammonium adducts which are better substrates for fragmentation reactions giving rise to qualifiers and/or quantifiers for the quantification of organic compounds with better sensitivity, highly improved specificity and better linearity of the calibration curve.

Another novel feature of the present work is an appreciable increase in the sensitivity of compounds in general as a result of suppressed metal adduct formation and improved ionization. Needless to mention that the formation of several adducts such as $[\mathrm{M}+\mathrm{H}]^{+},[\mathrm{M}+\mathrm{Na}]^{+},[\mathrm{M}+\mathrm{K}]^{+},\left[\mathrm{M}+\mathrm{NH}_{4}\right]$ ${ }^{+}$etc. can and does lead to sensitivity loss since the signal intensity of an analyte gets distributed across several adducts. It was difficult to predict the percentage increase in the sensitivity of the compounds studied since sensitivity in mass spec- 
Marwah, P. et al. / J. Appl. \& Nat. Sci. 12(2): 180 - 192 (2020)
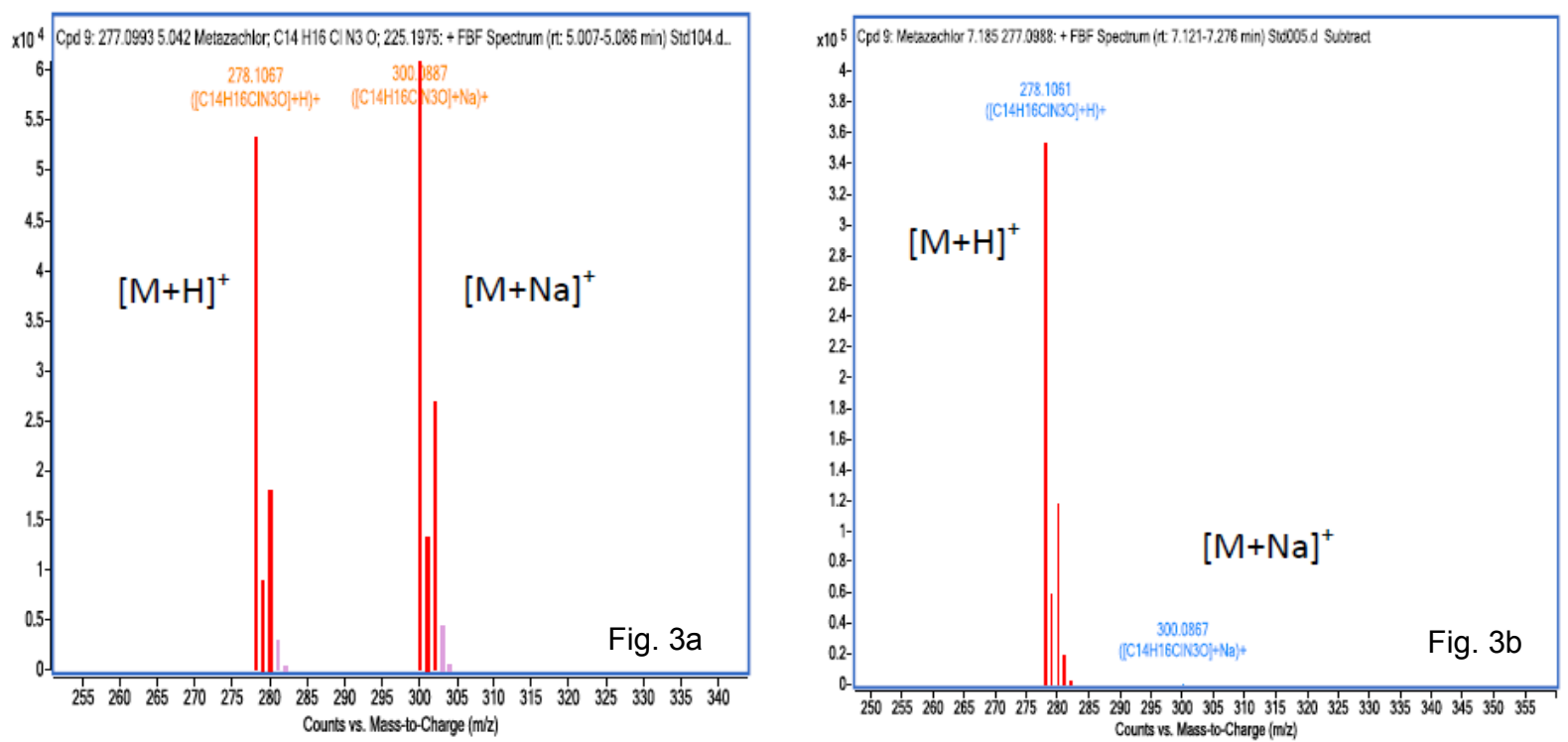

Fig. 3. Mass spectrum of Metazachlor obtained using water-95\% methanol with $0.1 \%$ acetic acid gradient (Fig 3a) and using a cocktail of formic acid, trifluoroacetic acid, heptafluorobutyric acid and ammoniumacetae in water-methanol gradient (Fig. 3b). Near absence of $[\mathrm{M}+\mathrm{Na}]^{+}$and total absence of $[\mathrm{M}+\mathrm{K}]^{+}$adducts was obseved. Complete LC-MS details under experimental section.
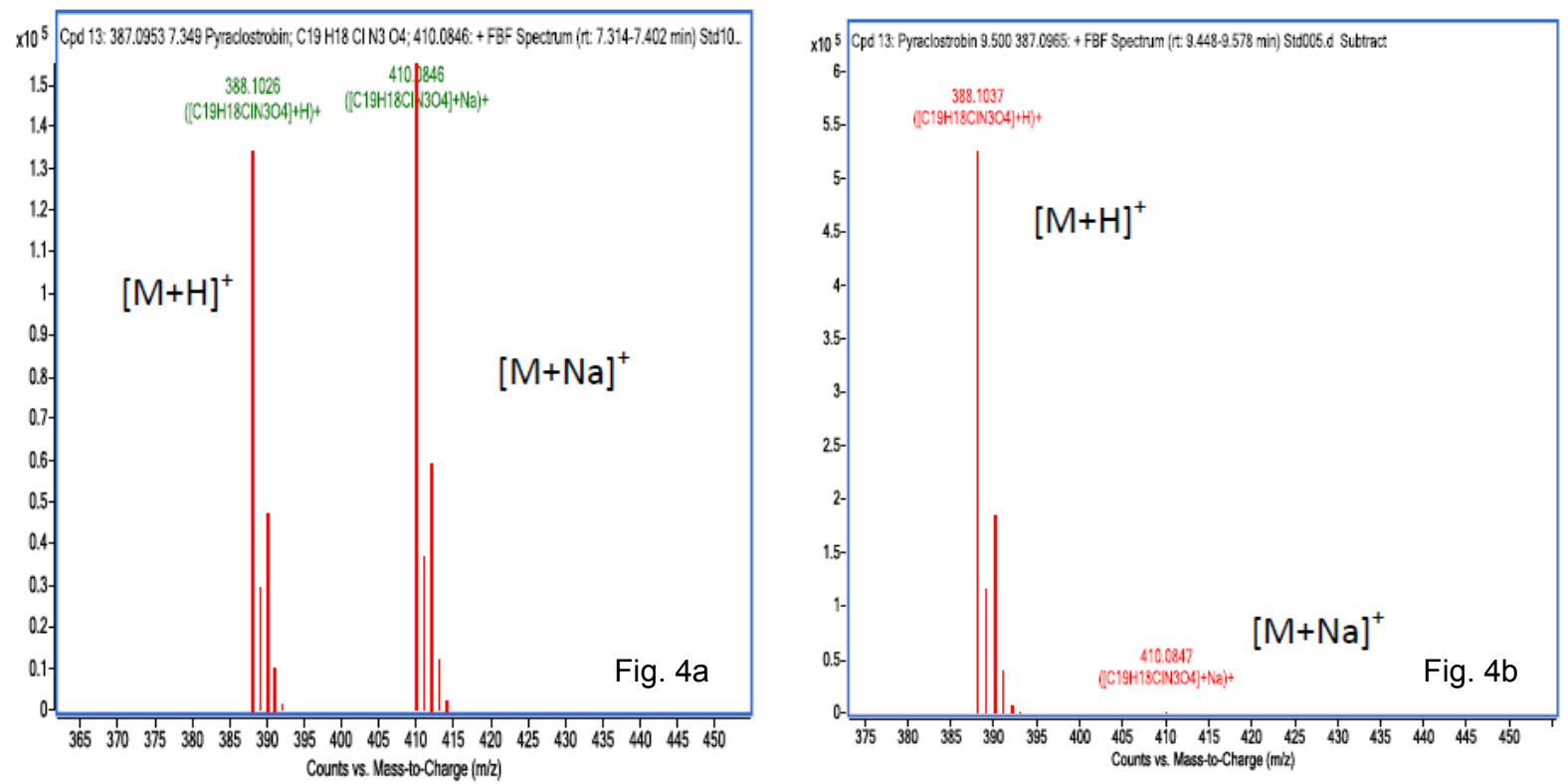

Fig. 4. Mass spectrum of Pyraclostrobin obtained using water-95\% methanol with $0.1 \%$ acetic acid gradient (Fig 4a) and using a cocktail of formic acid, trifluoroacetic acid, heptafluorobutyric acid and ammoniumacetae in water-methanol gradient (Fig. 4b). Near absence of $[\mathrm{M}+\mathrm{Na}]^{+}$and total absence of $[\mathrm{M}+\mathrm{K}]^{+}$adducts was obseved. Complete LC-MS details under experimental section.

trometry is a unique function of multiple parameters including but not limited to flow rates of liquids and gas, electronic parameters, $\mathrm{pH}$ of the system, composition of mobile phase etc. Nevertheless, increase in sensitivity was observed across a wide spectrum of compounds and was in general more than $30 \%$ and some times more than $100 \%$ (Fig. 9). The use of this novel cocktail results in better limits of detection and quantitation than those obtained using conventional techniques.

\section{Conclusion}

The use of fluorinated alkanoic acids along with formic acid and volatile ammonium salts of lower alkanoic acids was found to be extremely useful in suppressing metal adduct formation in positive ion mode of electrospray ionization mode of liquid chromatography mass spectrometry (ESI-LC-MS). The extremely high electronegativity of fluorine atom and unique electrostatic nature of $\mathrm{C}-\mathrm{F}$ bond coupled with stereoelectronic interactions 
Marwah, P. et al. / J. Appl. \& Nat. Sci. 12(2): 180 - 192 (2020)
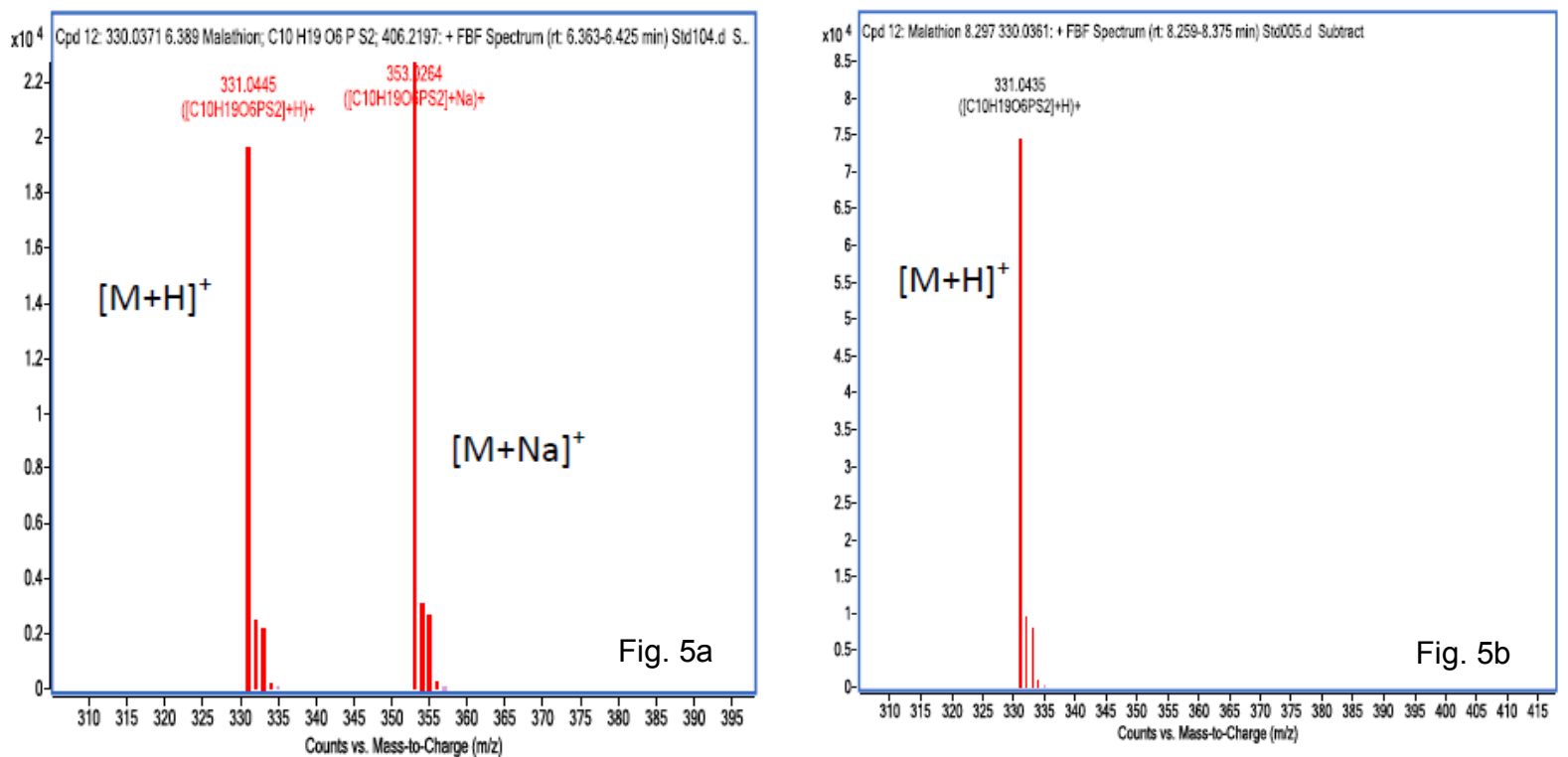

Fig. 5. Mass spectrum of Malathion obtained using water $95 \%$ methanol with0.1\% acetic acid gradient (Fig 5a) and using a cocktail of formic acid, trifluoroacetic acid, heptafluorobutyric acid and ammoniumacetae in watermethanol gradient (Fig. 5b). Total absence of $[\mathrm{M}+\mathrm{Na}]^{+}$and $[\mathrm{M}+\mathrm{K}]^{+}$adducts was obseved. Complete LC-MS details under experimental section.
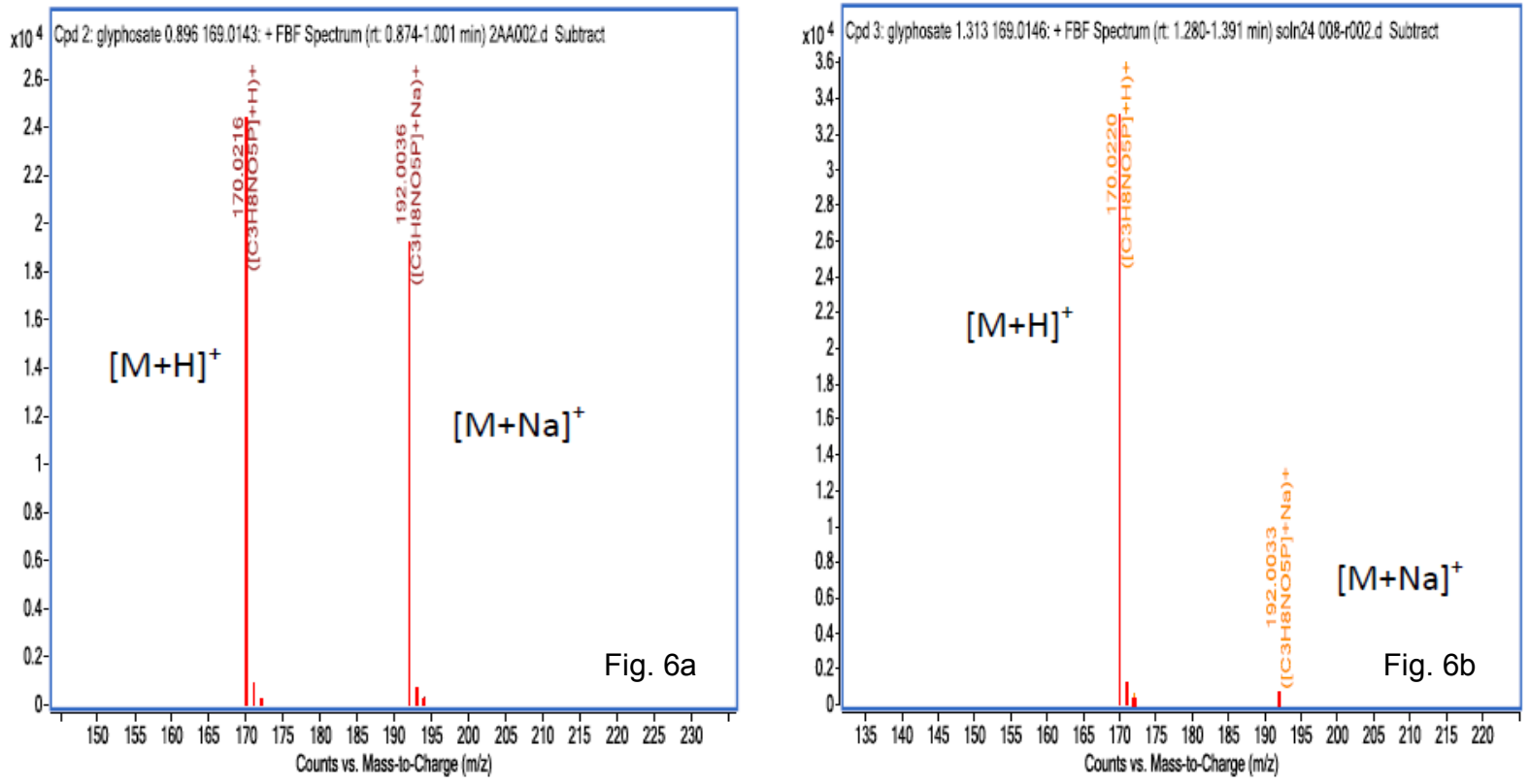

Fig. 6. Mass spectrum of Glyphosate (water soluble, amphoteric, highly polar herbicide) obtained using $5 \%$ methanol in $0.1 \%$ formic acid (Fig 6a) and using a cocktail of formic acid, trifluoroacetic acid, heptafluorobutyric acid and ammoniumacetae in water-methanol gradient (Fig. 6b). Near absence of $[\mathrm{M}+\mathrm{Na}]^{+}$and total absence of $[M+K]^{+}$adducts was obseved. Complete $L C-M S$ details under experimental section.

(hyperconjugation) with neighboring bonds or lone pairs enables the polyfluorinated alkanoic acids in trapping highly electropositive ions $\left(\mathrm{Na}^{+}\right.$, $\mathrm{K}^{+}$) letting proton do its job efficiently. A cocktail consisting of formic acid, trifluoroacetic acid, heptafluorobutyric acid and ammonium acetate was found to be extremely effective in controlling metal ion adducts and producing $[\mathrm{M}+\mathrm{H}]^{+}$ions exclusively most of the times The present work is cost effective and exhibits an array of additional useful features such as creating good quality peak chromatogram, excellent reproducibility, lower limits of quantitation/detection as well as operational simplicity. A characteristic feature is significant increase in sensitivity by virtue of suppressing metal adduct formation. This technique has been successfully used in our laboratory for the estimation of targeted and nontargeted 

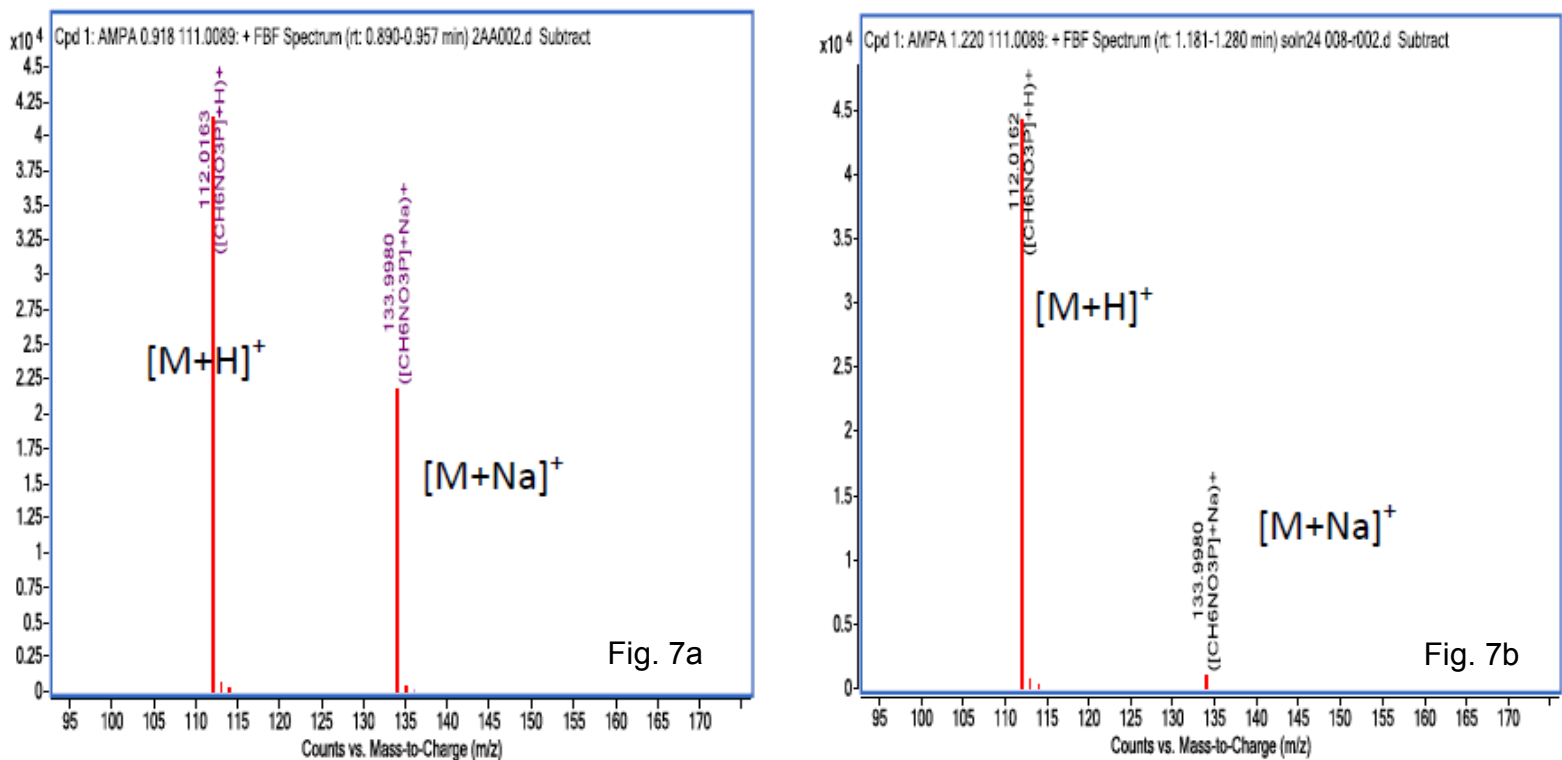

Fig. 7. Mass spectrum of Aminomethylphosphonic acid (AMPA, a highly polar, amphoteric, water soluble) obtained using $5 \%$ methanol in $0.1 \%$ Formic acid gradient (Fig 7a) and using a cocktail of formic acid, trifluoroacetic acid, heptafluorobutyric acid and ammoniumacetae in water-methanol gradient (Fig. 7b). Near absence of $[\mathrm{M}+\mathrm{Na}]^{+}$and total absence of $[\mathrm{M}+\mathrm{K}]^{+}$adducts was obseved. Complete LC-MS details under experimental section.
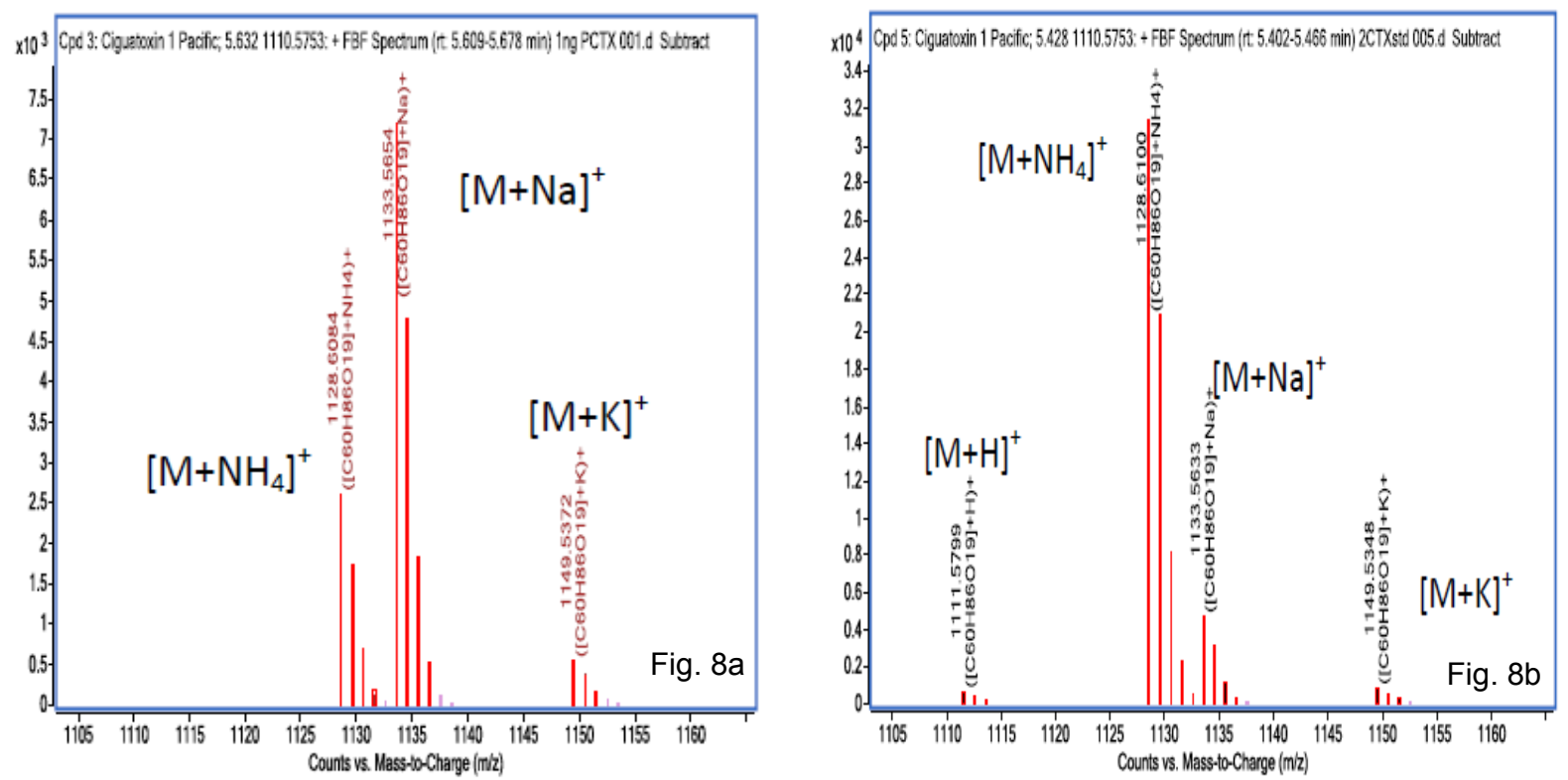

Fig. 8. Mass spectrum of of Pecific-Ciguatoxin-1 (MW1128.61) obtained using water-95\% acetonitrile with $0.1 \%$ formic acid gradient (Fig 8a) and using a cocktail of formic acid, trifluoroacetic acid, heptafluorobutyric acid and ammoniumacetae in water-95\% acetonitrile gradient (Fig. 8b). Ammonium adduct $\left[\mathrm{M}+\mathrm{NH}_{4}\right]^{+}$was observed as major adduct with highly significant reduction in the formation of $[\mathrm{M}+\mathrm{Na}]^{+}$and $[\mathrm{M}+\mathrm{K}]^{+}$adducts. Complete $L C-M S$ details under experimental section.

analysis of pesticides, marine toxins, drugs and pharmaceuticals etc. in various matrices including environmental waters using LC-MS-TOF and triple quadruples (QQQ). It will greatly help the scientist involved in quantitative method development and validation in developing reproducible and robust validated methods in all kinds of biological matrices.

\section{REFERENCES}

1. Banerjee, S. and Mazumdar, S. (2012). Electrospray Ionization Mass Spectrometry: A technique to access the information beyond the molecular weight of the analyte. Int. J. Analytical Chem., Article ID 282574, 40 pages. doi: 10.1155/2012/282574.

2. Becker, T. (2011). Methods for reducing adduct formation for mass spectrometry analysis. US patent, $7,888,127$ B2 


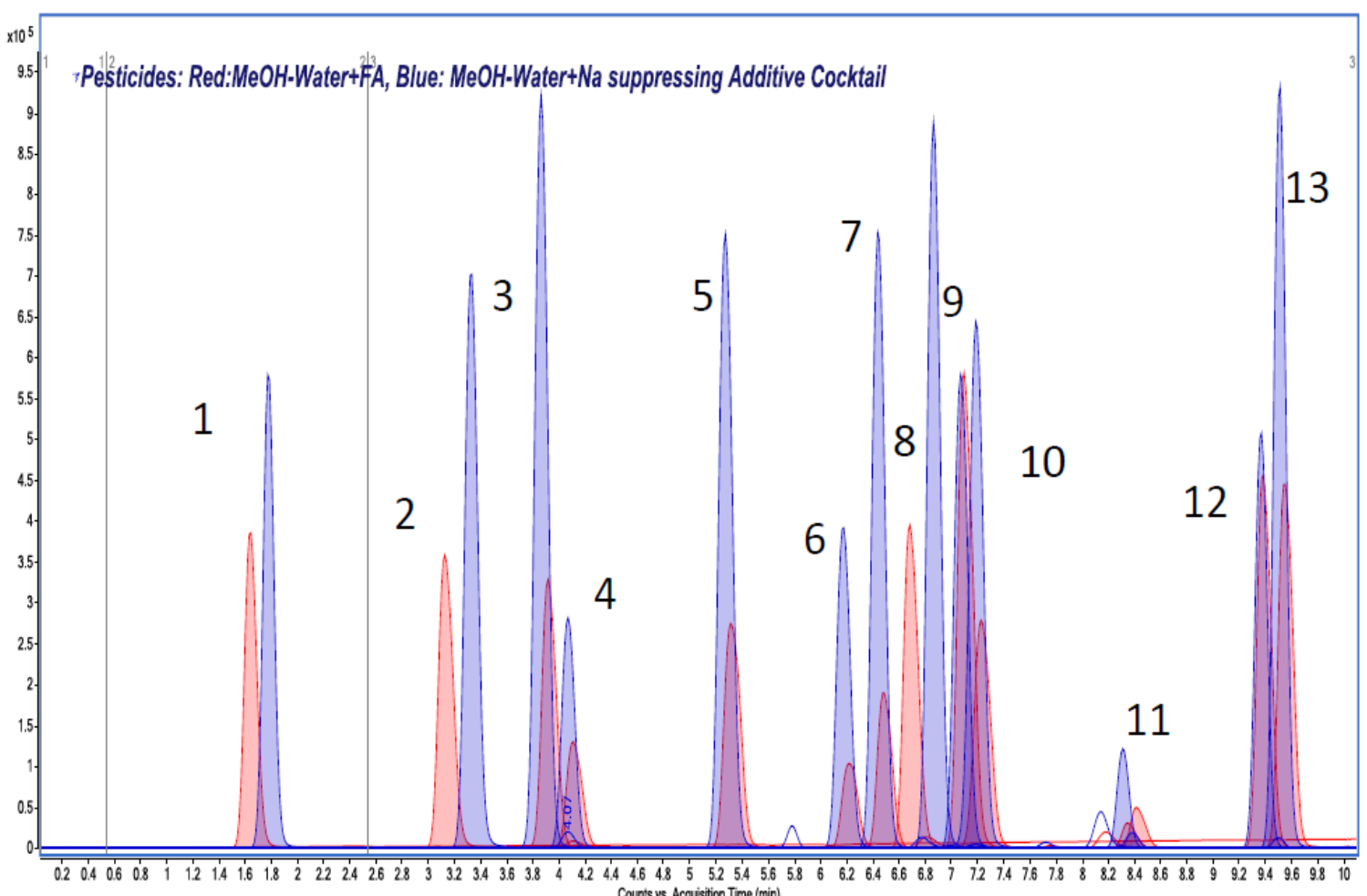

Fig 9. Increase in the sensitivity of the compounds under conditions of present invention. A mixture of about one dozen pesticides were analyzed in LC-MS-TOF. Red chromatogram : Using water-methanol-formic acid. Blue chromatogram: Results Using trifluoroacetic acid, formic acid heptafluorobutyric acid and ammonium acetate. Complete details are given in experimental section. 1: Aminocarb; 2: Thiabendazole, 3: Imazapyrr; 4: Dimethoate; 5: Metoxuron; 6: Carbofuran; 7: Metosulam; 8: Imazalil; 9: Atrazine; 10: Metazachlor; 11: Malathion; 12: Diazinon and 13: Pyraclostrobin.

3. Bester-Rogac, M. (2014). Ageing of Water or Dissolution of Glass: An Electrical Conductivity Study. Acta Chimica Slovenica, 61: 875-881.

4. Bohrer, D., Bortoluzzi, F., Nascimento P.V., Carvalho, M.L. and Ramirez, A.G. (2008) Silicate release from glass for pharmaceutical preparations. Int. J. Pharmaceutics 355: 174-183. doi:10.1016/ j.ijpharm.2007.12.025.

5. Dowling, G. (2017). Analysis of Bitterness Compounds by Mass Spectrometry. In: Bitterness: Perception, Chemistry and Food Processing (Aliani, M. and Eskin, M.N.A., eds). Wiley Online Library. https://doi.org/10.1002/9781118590263.ch8.

6. Dunitz, J.D. and Taylor, R (1997). Organic Fluorine Hardly Ever Accepts Hydrogen Bonds. Chem. A Eur. Journal, 3: 89-98. https://doi.org/10.1002/ chem.19970030115.

7. Erngren, I., Haglöf, J., Engskog, M.K.R., Nestor, M., Hedeland, M., Arvidsson, T. and Pettersson, C. (2019). Adduct formation in electrospray ionizationmass spectrometry with hydrophilic interaction liquid chromatography is strongly affected by the inorganic ion concentration of the samples. J. Chromatog. A, 1600: 174-182. doi: 10.1016/j.chroma.2019.04.049.

8. Escott, R.E.A. and Chandle, D.W. (1989). The Use of Ammonium Acetate as an lon-Pairing Electrolyte for Ethoxylated Surfactant Analysis by Thermospray LC/MS. J. Chromatog. Sci., 27: 134-138, https:// doi.org/10.1093/chromsci/27.3.134.

9. Gao, S., Zhan, Q., Li, J., Yang, Q., Li, X., Chen, W. and Sun, L. (2010)LC-MS/MS method for the simul- taneous determination of ethyl gallate and its major metabolite in rat plasma. Biomed. Chromatog. 24: 472-78. https://doi.org/10.1002/bmc.1314.

10. Holcapek, M. and Byrdwell, W.C. (2017) Eds. Handbook of Advanced Chromatography/Mass Spectrometry Techniques. Academic Press London, UK

11.Hua, W., Lerardi, T., Lesslie, M., Hoffman, B.T. and Mulvana, D. (2014). Development and validation of a HILIC-MS/MS method for quantification of decitabine in human plasma by using lithium adduct detection. $J$. Chromatog. B, 969: 117-122. doi: 10.1016/ j.jchromb.2014.08.012.

12.Jaikwang, P., Junkuy, A., Ratana Sapbamrer, R., Seesen, M., Khacha-ananda, S., Mueangkhiao, P. and Wunnapuk, K. (2020). A Dilute-and-Shoot LCMS/MS Method for Urinary Glyphosate and AMPA. Chromatographia Pub Date: 2020-01-08, DOI: 10.1007/s10337-019-03853-3.

13.Konermann, L. (2017). Addressing a Common Misconception: Ammonium Acetate as Neutral pH "Buffer" for Native Electrospray Mass Spectrometry. J. Am. Soc. Mass Spectrom. 28(9): 1827-1835. DOI: 10.1021/jasms.8b0565

14.Kruve, A., Kaupmees, K., Liigand, J., Oss, M. and Leito, I. (2013). Sodium adduct formation efficiency in ESI source. J. Mass Spectrom., 48: 695-702. DOI 10.1002/jms.3218.

15.Kruve, A. and Kaupmees, K. (2017) Adduct Formation in ESI/MS by Mobile Phase Additives. J. Am. Soc. Mass Spectrom., 28: 887-894. https:// doi.org/10.1007/s13361-017-1626-y. 
16.Lambert, W. (2004). Pitfalls in LC-MS(-MS) Analysis. $T+K, 71$ (2): 64-68.

17.Leitner, A., Emmert, J., Boerner, K. and Lindner, W. (2007). Influence of Solvent: Additive Composition on Chromatographic Separation and Sodium Adduct Formation of Peptides in HPLC-ESI MS. Chromatographia, 65: 649-653. DOI: 10.1365/s10337-0070219-50009-5893/07/06

18.Lemal, D.M. (2004) Perspective in fluorocarbon chemistry. J. Org. Chem. 69 (1): 1-11 https:// doi.org/10.1021/jo0302556.

19.Marwah, A., Marwah, P., \& Lardy, H. (2001). Liquid chromatography-electrospray ionization mass spectrometric analysis of corticosterone in rat plasma using selected ion monitoring. J. Chromatog. B: 757 (2): 333-342. doi:10.1016/s0378-4347(01)00171-2.

20.Marwah, A., Marwah, P., Lardy, H.A. (2002). Analysis of ergosteroids VIII: Enhancement of signal response of natural steroidal compounds in liquid chromatographic-electrospray ionization mass spectrometric analysis by mobile phase additives. J. Chromatography A, 964: 137-51. DOI: 10.1016/s00219673(02)00650-7.

21.Mortier, K.A., Zhang, G.F., Van Peteghem, C.H. and Lambert, W.E (2004). Adduct formation in quantitative bioanalysis: Effect of ionization conditions on paclitaxel. J. Am. Soc. Mass Spectrom., 15: 585. DOI: 10.1016/j.jasms.2003.12.013.

22.Murtada, K., Andrés, F. de, Galván, I., Ríos, A., Zougagh, M. LC-MS determination of catecholamines and related metabolites in red deer urine and hair extracted using magnetic multi-walled carbon nanotube poly(styrene-co-divinylbenzene) composite, J. Chromatog. B (2019), doi: https://doi.org/10.1016/ j.jchromb.2019.121878.

23.O'Hagan D (2008). "Understanding organofluorine chemistry. An introduction to the C-F bond". Chem Soc Rev. 37 (2): 308-19. doi:10.1039/b711844a. PMID 18197347.

24.Schugu, K. and McNair, H.M. (2002). Adduct formation in electrospray ionization. Part 1: Common acidic pharmaceuticals, J. Sep. Sci., 25:760-766. DOI: 10.1016/s0021-9673(02)01732-6.

25.Shou, W.Z. and Naidong, W. "Simple means to alle- viate sensitivity loss by trifluoroacetic acid (TFA) mobile phases in the hydrophilic interaction chromatography-electrospray tandem mass spectrometric (HILIC-ESI/MS/MS) bioanalysis of basic compounds," J. Chromatog. B, 825: 186-192. https:// doi.org/10.1016/j.jchromb.2005.01.011-766.

26.Siuzdak, G. (2003). The Expanding role of mass spectrometry in Biotechnology. MCC Press, San Diego USA.

27.Thompson, M.J. (2018). Mass Spectrometry. Pan Stanford Publishing, Singapore.

28.Turkmen, Z., Kuloglu, M., Tekin, T., Mercan, S. and Bavunoglu, I. (2020). A GC-MS method for illegal stimulant drugs from serum by a multi-drug use sample in Turkey. J. Chem. Metrol. 13:2 (2019) 6167. DOI: http://doi.org/10.25135/jcm.32.19.11.1499.

29.Vijlder, D.T, Valkenborg, D., Lemière, F., Romijn, E.P., Laukens K. and Cuyckens, F. (2018) A tutorial in small molecule identification via electrospray ionization-mass spectrometry: The practical art of structural elucidation. Mass Spectrom. Rev. 37(5):607629. doi: 10.1002/mas.21551. Epub 2017 Nov 9.

30.Vogesser, M. and Seger, C. (2010) Pitfalls associated with the use of liquid chromatography-tandem mass spectrometry in the clinical laboratory. Clin Chem. 56(8):1234-44. doi: 10.1373/ clinchem.2009.138602.

31.Yogi, K., Oshiro, N., Inafuku, Y., Hirama, M. and Yasumoto, T. (2011). Detailed LC-MS/MS Analysis of Ciguatoxins Revealing Distinct Regional and Species Characteristics in Fish and Causative Alga from the Pacific. Anal. Chem., 83: 8886-8891. doi.org/10.1021/ac200799j.

32.Yamin, T.S., Prihed, H., Madmon, M., Shifrovitch, A., Baratz, A. and Weissberg, A. (2019). Structural elucidation of phenidate analogues via the ESI-MS/ MS spectra of their sodium adduct ions. Forensic Sci. Int. 306, 110044. doi:10.1016/ j.forsciint.2019.110044.

33.Zhang, J-Z., Fischer, C.J. and Ortner, P.B. (1999) Laboratory glassware as a contaminant in silicate analysis of natural water samples. Wat. Res. 33: 2879-2883. https://doi.org/10.1016/S0043-1354(98) 00508-9. 